\title{
House-hold contact tuberculosis screening adherence and associated factors among tuberculosis patients attending at health facilities in Gondar town, northwest, Ethiopia
}

Dessie Alemnew Shiferaw ${ }^{1}$, Habtamu Sewunet Mekonnen ${ }^{2^{*}}$ (i) and Addisu Taye Abate ${ }^{2}$

\begin{abstract}
Background: Contacting patients with tuberculosis have a substantial risk of developing the disease. Household contact screening has recently been recommended as a strategy to enhance case detection in high-burden countries. But there is no enough information in Gondar town regarding household contact screening practice among TB patients.

Methods: An institution-based cross-sectional study was conducted from March 1 to 30, 2019 on 404 tuberculosis patients attending at health facilities in Gondar Town. Epi-Info version 7 for data entry and SPSS version 20 for data analysis were used. Descriptive statistics were carried out to illustrate the means, standard deviations, and frequencies. Bivariable and multivariable logistic regression analyses were used to identify significantly associated variables with the dependent variable.

Results: From 412 study populations, 404 were completed the study with $98.06 \%$ response rate. The overall household contact TB screening adherence was $47.5 \%(95 \% \mathrm{Cl}: 43.1,52.5)$. In the multivariable analysis, having certificate and above educational level $(A O R=2.83,95 \% \mathrm{Cl}: 1.40,5.67)$, having sufficient knowledge about TB ( $A O R=8.26,95 \% \mathrm{Cl}: 4.34,15.71)$, being satisfied with health care service (AOR $=3.26,95 \% \mathrm{Cl}: 1.58,6.76)$, health education given by health care workers $(A O R=2.60,95 \% \mathrm{Cl}: 1.54,4.40)$, and having HIV/AIDS co-infection ( $\mathrm{AOR}=3.54,95 \% \mathrm{Cl}: 1.70,7.39)$, were factors associated with household contact TB screening adherence.

Conclusion: Compared to other previous studies, the current finding was high but it was low as compared with WHO and Ethiopian Ministry of Health recommendations (all persons having TB contact should be screened). Educational status, knowledge on TB, satisfaction with delivered health care service, health education given by HCWs about TB and HIV/AIDS co-infection were factors associated with household contact TB screening practice. Thus, strengthening household TB contact screening and educational programs regarding the risk of getting TB infection from household contacts is crucial.
\end{abstract}

Keywords: Contact screening, Household, Adherence, Tuberculosis, Ethiopia

\footnotetext{
* Correspondence: habtsew@ymail.com

${ }^{2}$ Department of Medical Nursing, School of Nursing, College of Medicine and

Health Sciences, University of Gondar, Gondar, Ethiopia

Full list of author information is available at the end of the article
}

(c) The Author(s). 2019 Open Access This article is distributed under the terms of the Creative Commons Attribution 4.0 International License (http://creativecommons.org/licenses/by/4.0/), which permits unrestricted use, distribution, and reproduction in any medium, provided you give appropriate credit to the original author(s) and the source, provide a link to the Creative Commons license, and indicate if changes were made. The Creative Commons Public Domain Dedication waiver (http://creativecommons.org/publicdomain/zero/1.0/) applies to the data made available in this article, unless otherwise stated. 


\section{Background}

Tuberculosis is an airborne contagious disease mainly caused by Mycobacterium tuberculosis. When TB-infected individuals cough, sneeze and shout; Mycobacterium in the suspended air can enter the respiratory system of a nearby healthy person. There are two types of TB named pulmonary and extrapulmonary. Pulmonary tuberculosis occurs when Mycobacterium tuberculosis primarily attacks the lungs. However, it can spread to other organs causing extrapulmonary TB [1-3].

Globally, there were an estimated 10.0 million new cases of TB disease (also known as active TB) in 2017. Even though, tuberculosis is an easily preventable and treatable disease, it remains a major cause of morbidity and mortality in many countries and an important public health problem of the world. TB is one of the top 10 causes of death and it is responsible for 1,600,000 TB related global deaths in 2017 [3]. A study conducted in New Delhi revealed that contacts of pulmonary positive TB patients have significantly higher infection rates as compared to contacts of pulmonary negative TB patients [4].

Ethiopia is one of the 30 high-TB and multidrug resistance TB-burden countries. According to the 2017 World Health Organization (WHO) report, Ethiopia is the 10th from 30th high TB and HIV burden countries with an incidence of 177 per 100,000 among all forms of TB. Thus, the government of Ethiopia has given due attention for the prevention and control of TB and it is the priority health program of the country's Health Sector Development Program (HSDP) but is not fast enough to achieve 2020 stop TB strategy [5].

TB contact patients are the high-risk group to develop $\mathrm{TB}$, especially children less than 5 years and people living with HIV are at higher risk [6-8]. Household contacts with active TB cases are at high risk of getting TB disease [9, 10]. Major challenges to the successful control of TB includes; timely diagnosis and adequate treatment of active $\mathrm{TB}$ (the index case), contact investigation (CI) or screening of persons in close contact with the index case, and treatment of latent tuberculosis infection (LTBI) to prevent its progression to active disease [10]. These three core elements are the basis of TB control [11]. Contact investigation, as one of the core element, is an important policy of TB control and play an important role to decrease the incidence [12].

The magnitude of TB screening adherence in Thailand, Southeast Nigeria, Gambo rural hospital, and urban districts of Amhara region in Ethiopia was 52, 23.6, 55.7, $33.7 \%$ respectively [13-16]. Regarding the associated factors, marital status, religion, family income, relationship with contact, knowledge, sharing a bedroom and type of TB were significantly associated factors with TB screening adherence. Besides distance from health-care facilities, lack of transport, direct and indirect costs of health care all present barriers to access household contact screening [15-17].

Screening of specific risk groups like household contacts, have been part of the Stop TB Strategy since its launch in late 2012 [18, 19]. Despite, household contact TB screening adherence is an important component to achieve the strategy of stop TB, there is no study conducted in Gondar town health facilities regarding household contact screening adherence on TB patients. Few studies conducted in Ethiopia were on the magnitude of household contact screening practice and othrs were limited in numbers of factors that influence household contact screening adherence. Therefore, the aim of this study was to assess the magnitude of household contact screening adherence and associated factors among TB patients attending at health facilities in Gondar Town.

\section{Methods}

\section{Study design and period}

An institution-based cross-sectional study was conducted from March 1 to 30, 2019.

\section{Study area}

The study was conducted in Gondar town, Northwest Ethiopia. Gondar town is one of the historical towns in Ethiopia. It is found about $737-\mathrm{km}$ away from Addis Ababa. In the town, there are one governmental specialized Hospital, eight governmental health centers, one private Hospital, and one private clinic, which delivers anti TB treatment and screening service. Currently, about 483 TB patients attend in these health facilities, of those 412 were adults and had household contact history.

\section{Source population}

The source population constitutes all adult patients who have anti-TB treatment follow up at health institutions in Gondar town and had household contact.

\section{Study population}

All adult patients with TB who had household contact, anti-TB treatment follow up at health facilities in Gondar town and found during the specified study period.

\section{Inclusion criteria}

All adult patients with TB who had household contacts and anti-TB treatment follow up in Gondar town health facilities were included.

\section{Exclusion criteria}

Adult patients with TB who had household contacts and were critically ill and unable to communicate, patients start treatment at the day of data collection. 


\section{Sample size determination and sampling procedure} The sample size was determined using a single population proportion formula, taking $33.7 \%$ magnitude of household contact screening practice of a study conducted in Amhara Region, Northwest Ethiopia [16] with the following assumptions: 95\% CI and 5\% margin of error and by adding $10 \%$ none response rate. The total sample size was 379 . The study populations were 412 closes to the calculated sample. So, all the study populations were included in the study.

\section{Operational definition \\ Household contact}

A person who shared the same enclosed living space for one or more nights with the index case during the 3 months before the commencement of the current treatment episode $[16,20,21]$.

\section{Household contact TB screening adherence}

If the patient brought at least one household contact for TB screening and otherwise not-adherent [16].

\section{Patient with sufficient knowledge on TB}

A patient who answered greater than or equal to $80 \%$ of the given TB related knowledge questions [16].

\section{HIV AIDS co-infection}

Presence of confirmed HIV/AIDS along with TB [22].

\section{Waiting time}

Time taken to get service after the arrival of health facilities [13].

\section{Patients who were satisfied by the services delivered at health facilities}

Those respondents who scored points $\geq 75 \%$ of the given satisfaction related questions otherwise unsatisfied [23, 24].

\section{Index case}

Refers to TB patient who is initially diagnosed with infectious $\mathrm{TB}$, and around him, contact investigation for a potentially exposed individual is indicated [21].

\section{Data collection tool and procedures}

A pre-tested and structured interviewer-administered questionnaire was used. First the questionnaire was prepared in the English language and it was translated to the local language (Amharic); then to ensure its consistency it was re-translated to English language by language expert. The questionnaire had five sections; Socio-demographic characteristics of the participants, practice, personal and behavioral factors of the participants, health care system-related factors, disease and treatment conditions associated with the practice. Participants medical documents were reviewed to collect information about the type of TB, date of diagnosis and HIV/AIDS infection status, and to confirm the verbal reports of contact schreening status. Participants were interviewed after briefly explained the study purpose and getting consent from each individual patient.

\section{Data quality assurance}

To test the fitness of the questionnaire for the study settings, the questionnaire was pretested taking $5 \%$ of the sample (20 TB patients) in Addis Zemen Hospital and health center prior to the actual study. Two days training was given for data collectors and supervisors about the data collection tool and data collection procedures. The data were checked for its completeness and accuracy.

\section{Data processing and analysis}

After data collection, a questionnaire was checked for completeness and consistency. The data were entered in to Epi-Info version 7 and then export to SPSS version 20 software for analysis. Descriptive statistics were carried out to illustrate the means, standard deviations, and frequencies. Tables and figures were used to display the findings. Binary logistic regression analysis was done to identify variables having a significant association with the dependent variable. Then control the effect of confounding, all independent variables with a $p$-value less than 0.2 in the bivariate analysis were again entered to multivariable logistic regression. Finally, variables with $P$-value less than 0.05 considered as significantly associated factors. Hosmer and Lemeshow goodness of fit test was used for model fitness.

\section{Results}

Socio-demographic characteristics of respondents

From 412 study participants, 404 were complete the study with $98.06 \%$ response rate. Among the participants, 144 (35.6\%) were in the age group of $20-29$ years, with the mean age of 35.75 years $( \pm 14.28$ standard deviation). Two hundred twenty-one (54.7\%) males. Two hundred (49.5\%) of the participants were married and majority 386 (95.5\%) were Amhara by Ethnicity. One hundred thirty-two (32.7\%) were merchant by occupation $122(30.2 \%)$ participants had a primary school educational status. From all study participants, 283 (70\%) had > = 1001 ETB average monthly income. About 210 (52\%) of respondents had contact relationship with their son/daughter (Table 1).

\section{Personal, health care system and disease-related characteristics}

From a total of 404 study participants, 285 (70.5\%) had sufficient knowledge about TB. Concerning to causes of TB $209(51.7 \%)$ believed that bacteria cause it and $348(86.1 \%)$ of them perceived as TB is transmitted through infectious droplets released from TB patients. Majority, 332(82.2\%) of 
Table 1 Socio-demographic characteristics of Tuberculosis patients attending at health facilities in Gondar Town, Northwest Ethiopia, March $2019(n=404)$

\begin{tabular}{lll}
\hline Variables & Frequency $(\mathrm{n})$ & Percent (\%) \\
\hline Age & 17 & \\
$<20$ & 144 & 4.2 \\
$20-29$ & 108 & 35.6 \\
$30-39$ & 61 & 26.7 \\
$40-49$ & 74 & 15.1 \\
$>=50$ & & 18.3 \\
Sex & 221 & \\
Male & 183 & 54.7 \\
Female & & 45.3 \\
Marital status & 147 & \\
Single & 200 & 36.4 \\
Married & 43 & 49.5 \\
Divorced & 14 & 10.6 \\
Widowed & & 3.5
\end{tabular}

Ethnicity

Amhara

Oromo

Educational status

No formal education

Primary

Secondary

Certificate and above

89

Occupation

Governmental Employed $\quad 68$

Farmer

Merchant

Student

Housewife

Daily laborer

Family monthly income(Ethiopian Birr)

$$
<=300
$$

$301-600$

$601-1000$

$>=1001$

Relationship of household contacts with respondents

\begin{tabular}{lll} 
Spouse & 184 & 45.5 \\
Father & 56 & 13.9 \\
Mother & 96 & 23.8 \\
Sister/brothers & 32 & 7.9 \\
Relatives & 52 & 12.9 \\
Son/daughter & 210 & 52.0 \\
Friends & 97 & 24 \\
\hline
\end{tabular}

the participants were satisfied with TB clinic service. Two hundred (49.5\%) and 152(37.6\%) were patients with drugsensitive Pulmonary Tuberculosis (PTB) and drug-sensitive extrapulmonary tuberculosis (EPTB) respectively. Two hundred forty $(59.4 \%)$ participants were on a continuation phase of anti TB treatment. Regarding HIV/AIDS coinfection status of the participants, $60(14.9 \%)$ of were HIV infected along with TB. (Table 2).

\section{Household contact TB screening adherence}

In this study, the overall prevalence of household contact screening adherence was $47.5 \%$ (95\% CI: 43.1, 52.5). The mean number of household contacts of participants was 3.56 with a Standard Deviation of \pm 2.09 and the

Table 2 Personal, Health care system-related characteristics of respondents, health facilities in Gondar Town, Northwest Ethiopia, March 2019( $n=404)$

\begin{tabular}{lll}
\hline Variables & Frequency $(\mathrm{n})$ & Percent $(\%)$ \\
\hline Knowledge of TB & & \\
Sufficient & 285 & 70.5 \\
Insufficient & 119 & 29.5
\end{tabular}

Patient satisfaction by service delivered at health facilities

$\begin{array}{lll}\text { Satisfied } & 335 & 82.9 \\ \text { Unsatisfied } & 69 & 17.1\end{array}$

Type of health facility

Governmental hospital $\quad 130 \quad 32.2$

Governmental health center $\quad 250 \quad 61.9$

$\begin{array}{lll}\text { Private hospital } & 11 & 2.7\end{array}$

$\begin{array}{lll}\text { Private clinic } & 13 & 3.2\end{array}$

Mode of transportation

On foot $222 \quad 55.0$

$\begin{array}{lll}\text { Public transport } & 182 & 45.0\end{array}$

Health education about TB

$\begin{array}{lll}\text { Yes } & 253 & 62.6\end{array}$

$\begin{array}{lll}\text { No } & 151 & 37.4\end{array}$

Waiting time at TB clinic

$\begin{array}{lll}<60 \mathrm{~min} & 332 & 82.2 \\ >=60 \mathrm{~min} & 72 & 17.8\end{array}$

Type of TB

$\begin{array}{lll}\text { Drug sensitive PTB } & 200 & 49.5\end{array}$

Drug sensitive EPTB $\quad 152 \quad 37.6$

$\begin{array}{lll}\text { MDR TB } & 52 & 12.9\end{array}$

Phase of TB treatment

Intensive phase $\quad 164 \quad 40.6$

$\begin{array}{lll}\text { Continuation phase } & 240 & 59.4\end{array}$

HIV co -infection

$\begin{array}{lll}\text { Yes } & 60 & 14.9\end{array}$

No

344

$85.1^{\prime}$ 
mean number of household contacts brought for screening purpose was 2.16 with Standard Deviation of \pm 1.24 .

\section{Factors associated with household contact TB screening adherence}

In the bivariable logistic regression analysis, household contact-screening adherence was significantly associated with educational status, knowledge about $\mathrm{TB}$, health education given by health care workers about TB, patient satisfaction by health facilities service, type of tuberculosis, and HIV/AIDS co-infection.

However, in multivariable logistic regression, educational status, knowledge about TB, health education is given by health care workers about TB, patient satisfaction by health facilities service, and HIV/AIDS co-infection were significantly associated with household contact screening practice. Participants who had a certificate and above educational level were nearly three times more likely to practice household contact screening as compared with who were not formally educated $(\mathrm{AOR}=2.82$, $95 \%$ CI: 1.40, 5.67). Patients with sufficient knowledge on TB were eight times (AOR $=8.26,95 \% \mathrm{CI}: 4.34,15.72)$ more likely to practice household contact screening as compared with who had insufficient knowledge. Participants who were satisfied by delivered health care services were three times $(\mathrm{AOR}=3.26,95 \% \mathrm{CI}$ : $1.58,6.76)$ more likely to practice household contact screening as compared to patients who were not satisfied.

Patients who took health education from HCWs were nearly three times $(\mathrm{AOR}=2.60,95 \% \mathrm{CI}: 1.54,4.40)$ more likely to practice household contact screening as compared to patients who did not take health education. Patients who had HIV/AIDS co-infection were 3.5 times $(\mathrm{AOR}=3.54,95 \% \mathrm{CI}: 1.70,7.39)$ more likely to practice household contact screening as compared to patients who had no HIV/AIDS co-infection (Table 3).

\section{Discussion}

The overall household contact screening practice was 47.5\% (95\% CI:42.2,52.2). The finding was in-line with the practice level reported in Bangkok, Thailand (52\%) [13]. This finding was exceeded the findings of Enugu and Ebonyi States, Southeast Nigeria and in Amhara region (23.6, $33.7 \%$,) respectively $[14,16]$. The possible explanations could be differences in socio-cultural status of the index cases and health policy and health care system in the countries as well in study settings. The study in Southeast Nigeria was done only in governmental facilities but the current study was done in both governmental and private facilities. Besides, it could be due to time period in which studies in South Nigeria and Amhara region were done before 5 years In contrast, it was lower compared to a study done from Gambo Rural Hospital, Ethiopia which showed that $55.7 \%$ of the index cases brought at least one household contact for screening [15]. This difference might be due to the study design and source of information differences for the studies. The study done in Gambo rural Hospital was done by logbook review/taking secondary data and it was done only in governmental hospital but the current study is the primary data and it was done in both governmental and private Hospitals and health centers.

Educational status of respondents was significantly associated with household contact screening practice. Tuberculosis patients who had a certificate and above level of education were nearly three times more likely to practice household contact screening as compared to who had no formal education. This might be due to educated individuals read and listen to routine distributed information on TB through different media and easily understand risks for $\mathrm{TB}$ transmission and the benefits of contact investigation [16].

In this study, Knowledge of participants about TB and its' treatment were found to be the factor for household contact tuberculosis screening practice. Thus, patients who had sufficient knowledge about tuberculosis were eight times more likely to practice household contact screening as compared to who had insufficient knowledge about TB. The Comparable finding was obtained from a study conducted in Amhara region, Northern Ethiopia two times more likely [16]. And in Bangkok, Thailand five times more likely to practice household contact tuberculosis screening as compared with who had no sufficient knowledge [13]. It was also consistent within Enugu, Southeast Nigeria revealed that knowledge about contact tracing has significant association on household contact screening practice [25].

Participants who had sufficient knowledge about TB had a good understanding of the risks of household contact for tuberculosis and the benefit of bringing household contact to TB screening among tuberculosis patients might contribute to their practice. In this study, patient satisfaction by health facilities service, plays a crucial role to practice household contact screening. Patients who were satisfied by health care service were three times more likely to practice household contact screening as compared to patients who were not satisfied. This might be because health care service satisfaction at health facilities might increase healthcare-seeking behavior among TB patients.

Health education given by HCWs was significantly associated with household contact TB screening adherence, as patients who took health education, were three times more likely to adhere to household contact screening. A similar study conducted in Vietnam showed that majority of the patients went for screening as a result of instructions provided by the health education [26]. This finding was also shown in another study done in 
Table 3 Bivariable and Multivariable logistic regression analysis of factors for household contact screening adherence, health facilities in Gondar Town, North West Ethiopia, March 2019 ( $n=404)$

\begin{tabular}{|c|c|c|c|c|}
\hline \multirow[t]{2}{*}{ Variable } & \multicolumn{2}{|c|}{ HHCS adherence } & \multirow[t]{2}{*}{$\operatorname{COR}(95 \% \mathrm{Cl})$} & \multirow[t]{2}{*}{ AOR $(95 \% \mathrm{Cl})$} \\
\hline & Yes & No & & \\
\hline \multicolumn{5}{|l|}{ Educational status } \\
\hline No formal education & 46 & 64 & 1 & 1 \\
\hline Primary education & 54 & 68 & $1.11(0.66,1.86)$ & $1.03(0.54,1.93)$ \\
\hline Secondary education & 37 & 46 & $1.12(0.63,1.99)$ & $1.09(0.54,2.20)$ \\
\hline Certificate and above & 55 & 34 & $2.25(1.27,3.99)$ & $2.82(1.40,5.67)^{* *}$ \\
\hline \multicolumn{5}{|l|}{ Marital status } \\
\hline Single & 67 & 80 & 1 & 1 \\
\hline Married & 103 & 97 & $0.79(0.52,1.21)$ & $0.88(0.6,2.01)$ \\
\hline Divorced & 15 & 28 & $1.56(0.77,3.17)$ & $1.70(0.90,4.11)$ \\
\hline Widowed & 7 & 7 & $0.84(0.28,2.51)$ & $1.47(0.36,3.22)$ \\
\hline \multicolumn{5}{|c|}{ Family monthly income (Ethiopian Birr) } \\
\hline$<=300$ & 8 & 19 & $2.33(0.99,5.49)$ & $2.60(0.89,6.54)$ \\
\hline $301-600$ & 16 & 22 & $1.35(0.68,2.67)$ & $2.92(0.78,3.70)$ \\
\hline $601-1000$ & 28 & 28 & $0.98(0.55,1.74)$ & $0.83(0.66,2.03)$ \\
\hline$>=1001$ & 140 & 143 & 1 & 1 \\
\hline \multicolumn{5}{|l|}{ Type of health facility } \\
\hline Governmental hospital & 63 & 67 & 1 & 1 \\
\hline Governmental health center & 118 & 132 & $1.05(0.69,1.61)$ & $1.45(0.77,1.82)$ \\
\hline Private hospital & 5 & 6 & $1.13(0.33,3.88)$ & $1.92(0.46,4.14)$ \\
\hline Private clinic & 6 & 7 & $1.10(0.35,3.44)$ & $1.32(0.60,3.99)$ \\
\hline \multicolumn{5}{|l|}{ Mode of transportation } \\
\hline On foot & 97 & 129 & $1.65(0.98,2.45)$ & $1.74(0.85,3.33)$ \\
\hline Public transport & 99 & 3 & 1 & 1 \\
\hline \multicolumn{5}{|l|}{ Knowledge on TB } \\
\hline Sufficient & 176 & 109 & $10.39(5.83,18.53)$ & $8.26(4.34,15.72)^{* *}$ \\
\hline Insufficient & 16 & 103 & 1 & 1 \\
\hline \multicolumn{5}{|c|}{ Patient satisfaction by health care service } \\
\hline Yes & 178 & 157 & $4.45(2.39,8.32)$ & $3.26(1.58,6.76)^{* *}$ \\
\hline No & 14 & 55 & 1 & 1 \\
\hline \multicolumn{5}{|c|}{ Health education about TB by HCW } \\
\hline Yes & 155 & 98 & $4.87(3.11,7.63)$ & $2.60(1.54,4.40)^{* *}$ \\
\hline No & 37 & 114 & 1 & 1 \\
\hline \multicolumn{5}{|l|}{ Type of Tuberculosis } \\
\hline Drug-sensitive PTB & 93 & 107 & 1 & 1 \\
\hline Drug-sensitive EPTB & 65 & 87 & $0.86(0.56,1.31)$ & $1.09(0.65,1.83)$ \\
\hline MDR TB & 34 & 18 & $2.17(1.15,4.10)$ & $1.54(0.72,3.31)$ \\
\hline \multicolumn{5}{|l|}{ Phase of TB treatment } \\
\hline Intensive phase & 69 & 95 & $1.45(0.97,2.16)$ & $1.67(0.70(2.63)$ \\
\hline Continuation phase & 123 & 117 & 1 & 1 \\
\hline \multicolumn{5}{|l|}{ HIV/AIDS co infection } \\
\hline Yes & 40 & 20 & $2.53(1.42,4.50)$ & $3 \cdot 54(1.70,7 \cdot 39)^{* *}$ \\
\hline No & 152 & 192 & 1 & 1 \\
\hline
\end{tabular}


Southeast Nigeria [25]. This finding was also consistent with a study conducted in Northern Ethiopia. It revealed that awareness creation about contact tracing has a significant association with household contact screening adherence [16]. This might be due to health education about TB at health facilities that focus on signs and symptoms of $\mathrm{TB}$, the advantage of early screening and $\mathrm{TB}$ infection prevention techniques so those awareness creation activities might increase household contact TB screening practice among TB patients.

In this study, the household contact TB screening adherence among HIV infected participants was nearly four times more likely to practice household contact TB screening as compared with non-infected participants. This might be since HIV infected patients have regular visits to a health facility for antiretroviral therapy follow up. This implies that when patients came to health facilities frequently, their awareness about household contact screening practice also increased.

\section{Limitations of the study}

In this study there may be social desirability bias from participants towards which they assumed good response even though; we tried to overcome by select data collectors from health professionals working outside the TB clinic. In addition, this study did not included the determinant factors of household TB contact members.

\section{Conclusion}

The overall household contact TB screening practice was $47.5 \%$ (95\% CI: 43.1, 52.5). As compared to other previous studies findings, household contact screening practice among tuberculosis patients attending in Gondar Town health facilities was high but it was low as compared with WHO and Ethiopian Ministry of Health recommendations. Educational status, knowledge on TB, satisfaction with delivered health care service, health education given by HCWs about TB and HIV/AIDS coinfection were factors associated with household contact TB screening practice. Therefore, strengthening household TB contact screening and educational programs regarding the risk of getting TB infection from household contacts is mandatory.

\section{Abbreviations \\ AOR: Adjusted Odds Ratio; Cl: Confidence Interval; COR: Crude Odds Ratio; EPT: Extrapulmonary Tuberculosis; HCW: Health Care Worker; HIV: Human Immune Deficiency Virus; HIV/AIDS: Human Immune Deficiency Virus/ Acquired Immuno-deficiency syndrome; HSDP: Health Sector Development Program; MDR-TB: Multidrug Resistance Tuberculosis; OR: Odds Ratio; PTB: Pulmonary Tuberculosis; SD: Standard Deviation; SPSS: Statistical Package for Social Sciences; TB: Tuberculosis; WHO: World Health Organization}

\section{Acknowledgments}

Authors would like to express our gratitude to Amhara Regional Health Bureau for the fund and the University of Gondar College of Medicine and
Health Science School of Nursing Research and Ethical Review Committee for the approval of the ethical clearance. The authors would like to thank data collectors and supervisors for their commitment and the study participants for their valuable information.

\section{Ethical approval and consent to participate}

Ethical clearance was obtained from the ethical review committee of the School of nursing on behalf of the University of Gondar. An official letter was obtained from the School of nursing and was communicated with the selected health facilities in Gondar town. Participants were asked to involve in the study voluntarily and told as they had a right to withdraw at any time from the study without any consideration. The data were collected only after they gave their written consent to participate. Interview was performed at a suitable and secured place for respondents. Participants were guaranteed for confidentiality and they were assured that identifying information would not be made available to anyone who is not directly involved.

\section{Consent to publish}

Not Applicable.

\section{Authors' contributions}

DAS designed the study, developed the proposal, participated in the data collection, performed analysis, and drafted the manuscript. HSM and ATA approved the proposal with revisions, participated in data analysis and revised subsequent drafts of the manuscript. All authors read and approved the final manuscript.

\section{Funding}

This study was funded by the Amhara Regional Health Bureau. However, the funder had no role in study design, data collection, analysis, preparation of the manuscript and decision to publish.

\section{Availability of data and materials}

The raw data would not be provided for the reason of protecting patients confidentiality. But the summary data are available in the main document.

\section{Competing interests}

The authors declare that they have no competing interest.

\section{Author details}

${ }^{1}$ Department of Nursing, Debre-Tabor Health Science College, Debre-Tabor, Ethiopia. ${ }^{2}$ Department of Medical Nursing, School of Nursing, College of Medicine and Health Sciences, University of Gondar, Gondar, Ethiopia.

Received: 24 July 2019 Accepted: 9 December 2019

Received: 24 July 2019 Accepted: 9 Decem

References

1. Chinenye NM. Evaluation of Knowledge, Attitude and Practices of TB Diagnosed Patients in Rwanda towards TB Infection. Case of TB Diagnosed Patients in Kigali Urban and Rural Health Facilities. Int J Sci Res Publ. 2015;5(8).

2. Thorn P. Overcoming tuberculosis: a handbook for patients. London: Stop TB partnership; 2007. http://www.stoptb.org/assets/documents/resources/ publications/acsm/overcomingTB.pdf.

3. Organization WH. Global tuberculosis report 2017. 2017. Google Scholar 2018.

4. Dhingra V, Rajpal S, Aggarwal N, Taneja D. Tuberculosis trend among household contacts of TB patients. Indian J Community Med. 2004;29:44-8.

5. Institute Ethiopian Public Health Institute. Implementation guideline for GeneXpert MTB/RIF assay in Ethiopia. 2014. http://www.ephi.gov.et/images/ pictures/Implementation\%20Guideline\%20for\%20\%20GeneXpert\%2 OMTBRIF\%20Assay\%20in\%20\%20Ethiopia\%20Nov\%2003\%202....pdf.

6. Nair D, Rajshekhar N, Klinton JS, Watson B, Velayutham B, Tripathy JP, et al. Household contact screening and yield of tuberculosis cases-a clinic based study in Chennai, South India. PloS One. 2016;11(9):e0162090.

7. Caldeira ZM, Sant'Anna CC, Aidé MA. Tuberculosis contact tracing among children and adolescents, Brazil. Rev Saude Publica. 2004;38(3):339-45.

8. Gupta M, Saibannavar AA, Kumar V. Household symptomatic contact screening of newly diagnosed sputum smears positive tuberculosis patients-an effective case detection tool. Lung India. 2016;33(2):159.

9. Barroso EG. Factors associated with household Contacts' tuberculosis testing and evaluation; 2018. 
10. Fox GJ, Nhung NV, Loi NT, Sy DN, Britton WJ, Marks GB. Barriers to adherence with tuberculosis contact investigation in six provinces of Vietnam: a nested case-control study. BMC Infect Dis. 2015;15(1):103.

11. Association NTC. Guidelines for the investigation of contacts of persons with infectious tuberculosis. Recommendations from the National Tuberculosis Controllers Association and CDC. MMWR Recomm Rep. 2005;54(RR-15):1.

12. Fox GJ, Dobler CC, Marks GB. Active case finding in contacts of people with tuberculosis. Cochrane Database Syst Rev. 2011;9.

13. Tornee $S$, et al. Factors associated with the household contact screening adherence of tuberculosis patients. Southeast Asian J Trop Med Public Health. 2005;36(2):331-40.

14. Omotowo B, Ekwueme O, Aghaji M. Tuberculosis control mechanisms and contact tracing: knowledge and practice among TB patients at DOT centres is Southeast Nigeria. Sci Rep. 2012;9:1.

15. Ramos JM, et al. Screening for tuberculosis in family and household contacts in a rural area in Ethiopia over a 20-month period. Int J Mycobacteriology. 2013;2(4):240-3.

16. Gebregergs GB, Alemu WG. Household contact screening adherence among tuberculosis patients in northern Ethiopia. PLoS One. 2015;10(5):e0125767.

17. Mitchell E, den Boon S, Lonnroth K. Acceptability of household and community-based TB screening in high burden communities: a systematic literature review. WHO. 2013.

18. Fair E, Miller C, Ottmani S, Fox G, Hopewell P. Tuberculosis contact investigation in low-and middle-income countries: standardized definitions and indicators. Int J Tuberc Lung Dis. 2015;19(3):269-72.

19. World health organization. Recommendations for investigating contacts of persons with infectious tuberculosis in low-and middle-income countries. 2012. https:/www.who.int/tb/publications/2012/contact_investigation2012/en/.

20. Fair $\mathrm{E}$, et al. Tuberculosis contact investigation in low-and middle-income countries: standardized definitions and indicators. Int I Tuberc Lung Dis. 2015;19(3):269-72.

21. HEALTH FDROEMO. NATIONAL COMPREHENSIVE TUBERCULOSIS, LEPROSY AND TB/HIV TRAINING MANUAL for HEALTH CARE WORKERS. PARTICIPANTS MANUAL 2017.

22. Mekonnen HS, Azagew AW. Non-adherence to anti-tuberculosis treatment, reasons and associated factors among TB patients attending at Gondar town health centers, Northwest Ethiopia. BMC Res Notes. 2018:11(1):691.

23. Getahun B, Nkosi ZZ. Satisfaction of patients with directly observed treatment strategy in Addis Ababa, Ethiopia: a mixed-methods study. PLoS One. 2017:12(2):e0171209.

24. R7) SicfntoHAaTG. TB Patient Satisfaction Survey - Baseline Report 2014.

25. Ekwueme O-eC, Omotowo Bl, Agwuna KK. Strengthening contact tracing capacity of pulmonary tuberculosis patients in Enugu, Southeast Nigeria: a targeted and focused health education intervention study. BMC Public Health. 2014;14(1):1175

26. Thanh THT, Ngoc SD, Viet NN, Van HN, Horby P, Cobelens FG, et al. A household survey on screening practices of household contacts of smear positive tuberculosis patients in Vietnam. BMC Public Health. 2014;14(1):713.

\section{Publisher's Note}

Springer Nature remains neutral with regard to jurisdictional claims in published maps and institutional affiliations.

Ready to submit your research? Choose BMC and benefit from:
- fast, convenient online submission
- thorough peer review by experienced researchers in your field
- rapid publication on acceptance
- support for research data, including large and complex data types
- gold Open Access which fosters wider collaboration and increased citations
- maximum visibility for your research: over 100M website views per year
At BMC, research is always in progress.
Learn more biomedcentral.com/submissions

